\title{
IONTOPHORETIC TRANSDERMAL DELIVERY OF ANGIOTENSIN II AND ITS ANTAGONISTS
}

\author{
YI-YOU HUANG \\ Institute of Biomedical Engineering, College of Engineering, \\ National Taiwan University, Taipei, Taiwan
}

\begin{abstract}
Angiotensin II and its antagonists were used as permeant probes to investigate the mechanism of transdermal iontophoretic delivery of peptide/protein drugs and compare the effect of hydrophobic difference between the peptides drugs on the skin permeability. Transport of angiotensin II and its antagonists through excised rabbit pinna skin were enhanced with iontophoresis by monophase periodically pulsed current, amplituide $=1 \mathrm{~mA}$, frequency $=1000 \mathrm{~Hz}$ and on $/$ off ratio equals $50 \%$. The delivery rate was proportional both to the current intensity and pulse duration of the stimulation. Results showed that the permeation rate of [Sar, Ile] Angiotensin II $>$ [Sar,Ala]Angiotensin II > Angiotensin II. Iontophoretic mobility and hydrophobicity were the key factors dominating the transdermal iontophoretic delivery rate of angiotensin II and its antagonists.
\end{abstract}

Biomed Eng Appl Basis Comm, 2001 (October); 13: 242-247.

Keywords: Iontophoresis, Angiotensin II, Peptide drugs

\section{INTRODUCTION}

Iontophoresis is a method of drug delivery that uses an electric current to drive charged molecules, even uncharged molecules, across biologic membranes. Iontophoretic transdermal delivery is a noninvasive method which minimizes trauma, risk of infection, and damage to the skin. When a drug is administered by topical iontophoresis, the drug bypasses the digestive tract and escapes first-pass metabolism in the liver $[1,2]$. Effective use of iontophoresis depends upon the chemical properties of the drug. The drug must be electrically charged or in a solution sufficiently ionized so as to carry a measurable current in excess of $10(-10)$ $\mathrm{A}$ at physiologic $\mathrm{pH}$. Utilization of drugs with molecular weights exceeding 800 to 12,000 results in an uncertain rate of delivery [3]. However, research is underway investigating the possibility of transporting

Received: Aug. 20, 2001; accepted: Sep. 10, 2001

Correspondence: Yi-You Huang

Institute of Biomedical Engineering,

National Taiwan University Taipei, Taiwan peptides and proteins (such as insulin) by iontophoresis.

Charged molecules and ionic drugs, even neutral molecules, can be driven increasingly through skin into the body under an clectrical potential, either in continuous mode or pulsed mode. Iontophoretic transdermal drug delivery is a noninvasive method. It has potential advantage for long-term medication whereas needle insertion may cause anxiety, pain and may increase the risk of infection. For peptide/protein drug delivery, this technique is a promising method to provide a better way of administration because injection is always employed nowadays.

Besides, peptide/protein drugs become increasingly important in medication, the alternative administrations other than injection are gaining more attention. Iontophoretic transdermal delivery provides an attractive method for peptide delivery because it is noninvasive, avoids chemically hostile gastrointestinal environment, avoids hepatic elimination at first-pass. It also provides a controlled and/or sustained delivery, even in a pulsatile manner, which is critical for the desired physiological response of some hormonal drugs.

Green et al.[4] showed that normalized flux following cathodal iontophoresis of anionic amino acids were independent of lipophilicity, but might be in- 
versely related to molecular weight. For zwitterionic amino acids and neutral tripeptides, despite the large variation in lipophilicity, normalized flux is relatively constant. But we don't think the relationship is so simple. Turner et al., [5] anodal iontophoresis of poly-Llysines (polycations) demonstrated inverse dependence of iontophoretic delivery upon the MW of penetrant and might have a phenomenon of cut-off MW. They also showed that the electroosmotic flow (anode to cathode) would be inhibited even shut down by polycations. Angiotensin 2 and its antagonists were chosen to illustrate the feasibility of transdermal iontophoretic delivery because they may be regarded as stable model molecules for peptide delivery and their molecular weight were about 1000 , near the upper threshold of detectable passive permeation.

Clemessy et al., [6] found that under the current density of $0.28 \mathrm{~mA} / \mathrm{cm}^{2}$, the angiotensin II transport was be enhanced 20 -fold in comparison to passive permeation. The enhancement of permeation of peptide drugs by iontophoresis was proportional to the current density $[2,6,7]$. But the real mechanism of transport is still not clear even ambiguous [5,8].

In our early study, we had investigated the possibility of transdermal iontophoretic delivery of the smaller peptide, TRH (M.W.=362) [2]. Though there wasn't any detectable amounts of drug being permeated through excised skin during passive diffusion, the permeation amount of TRH increased with respect to time when an electrical field was applied. The permeation flux was proportional to the applied current density during iontophoresis. However, the factors affecting the iontophoretic permeation rate and the real mechanism of transport is still not clear. To investigate the feasibility and the mechanism of transdermal iontophoretic delivery of larger peptides, the transport pathways of peptide/protein drugs during iontophoresis and the effects of hydrophobicity/hydrophilicity of drugs, angiotensin II and its antagonists were used as a permeant probe. The molecular weight of angiotensin II and its antagonists were about 1000 daton, almost near the critical molecular weight of passive/active permeation margin. Moreover, angiotensin II was regarded as a stable model molecule for peptide delivery [6].

\section{MATERIALS AND METHODS}

Angiotensin II [Asp-Arg-Val-Tyr-Ile-His-Pro-Phe, $\mathrm{Mw} .=1046.2]$ and its antagonist [Sar, $\mathrm{Ala}$ ] angiotensin II [Sar-Arg-Val-Tyr-Ile-His-Pro-Ala, Mw. 926.1] and [Sar, Ile] angiotensin II [Sar-Arg-Val-Tyr-Ile-His-ProIle, Mw. 968.2] (Sigma, USA ) were used as model drugs for comparison. Other chemicals (reagent grade, Sigma, USA or Wako Chemicals, Japan) were used as received unless otherwise stated. Water was obtaincd from a purification system. Rabbit inner pinna skin were used in all experiments as its transdermal permeation characteristics are similar to human cadaverous skin (8). Skin was freshly excised from New Zealand white rabbits, about $3-5 \mathrm{~kg}$, obtained from our animal center in the College of Medicine. The outermost layers of skin (epidermis skin) were taken from the animals immediately after they were sacrificed and were used as soon as possible.

\subsection{Determination of iontophoretic flux in vitro}

The basic experimental arrangement is depicted in Figure 1. Iontophoretic diffusion experiments in vitro were made in the Valia-Chien side-by-side diffusion cell (model VSC-1, Crown Glass, Somerville, NJ), with a controlled rate of stirring $(600 \mathrm{rpm})$ in both half cells. Fresh skin was placed between the cells. An isothermal condition at $37 \pm 0.2{ }^{\circ} \mathrm{C}$ was maintained in both half-cells by circulating water of controlled temperature through a water jacket. An orifice $\left(0.69 \mathrm{~cm}^{2}\right)$ connected the two diffusion cells. The volume of each cell was $3.5 \mathrm{~mL}$. Angiotensin II and its antagonists with the same concentration, $10 \mathrm{mg} / \mathrm{ml}$ respectively, were poured into the donor compartment. Platinum wires (99.99\% purity; length $2 \mathrm{~cm} \times$ diameter $0.5 \mathrm{~mm}$ ) served as electrodes. The electrodes were connected to a universal power source, (HP 3245A, HewlettPackard, Palo Alto, CA), that output a periodically pulsed or constant current.

\subsection{Determination of Angiotensin II and Its an- tagonists}

Angiotensin II and its antagonists were assayed by capillary zone electrophoresis (P/ACE System 2100 , Beckman). UV detector at $214 \mathrm{~nm}$ was used and the temperature of the capillary was maintained at $30 \pm 0.1^{\circ} \mathrm{C}$. The separation buffer contained phosphate $(\mathrm{pH} 7.4)$ at an ionic strength $0.02 \mathrm{M}$. The sample was injected into the column under pressure for $5 \mathrm{~s}$, corresponding to approximately $30 \mathrm{~nL}$. All separations were performed

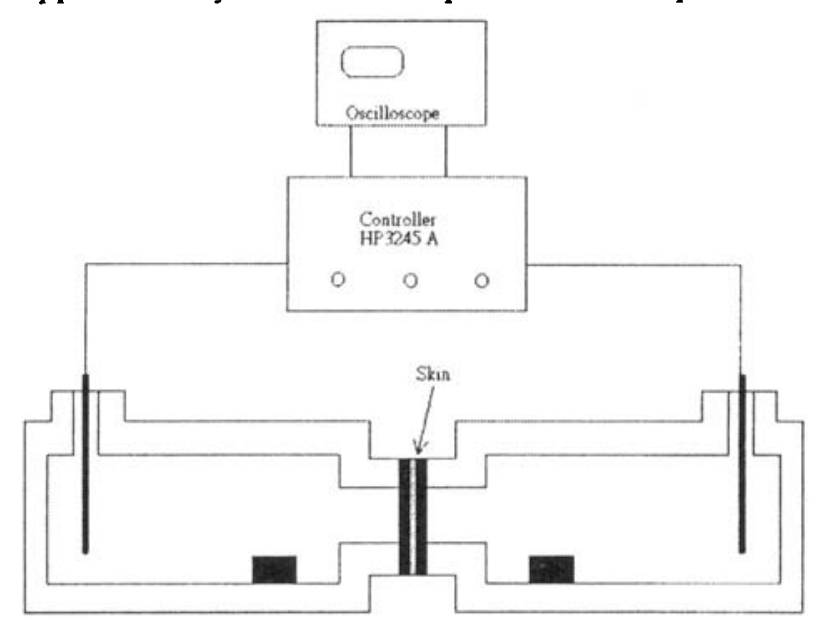

Fig. 1 Experimental setup. 
for $10 \mathrm{~min}$ at a constant voltage $15 \mathrm{kV}$. The retention time of Angiotensin II and its antagonists was about 9.90 and $8.84 \mathrm{~min}$ respectively. The sample signals were analyzed with software (Beckman System Gold, version 8.1).

\subsection{Thermal analysis of skin}

The thermal behavior of skin before and after iontophoresis was recorded using a differential scanning calorimeter (DSC2910, TA, New Castle, DE). The heating rate was $10^{\circ} \mathrm{C} / \mathrm{min}$ over a temperature range of $20-200^{\circ}$.

\section{RESULTS AND DISCUSSION}

Different mode of current could be used to enhance the permeation rate of drugs through the excised skin, either with a continuous mode of current or with a monophase periodically pulsed current. A continuous mode of current may cause electrochemical polarization in the skin that impedes the drug to penetrate. While monophase periodically pulsed current will depolarize the reverse electric field established between the skin. Depolarization of the skin during iontophoresis with pulsed current resulted in a significantly increased amount of transdermal delivery. In this study, monophase periodically pulsed current was used.

In a degradation test, the change of angiotensin 2 was monitored when angiotensin 2 was contacted with skin and deteriorated under the experimental condition: periodically monophase-pulse current, amplituide= $1 \mathrm{~mA}$, frequency $=1000 \mathrm{~Hz}$ and on/off ratio equals $50 \%$. During the experimental time interval, no significant change of angiotensin 2 was found. In some cases silver/silver chloride electrode would cause serious precipitation of peptides/proteins in iontophoresis $[9,10]$. While the electrode made of brass or steel (medical grade) would reveal small amounts of copper, nickle and chronium [11] which are well known dermal allergies. Platinum electrodes were used in this study. This inert electrode resulted in a shift of $\mathrm{pH}$ and gas bubbling from electric hydrolysis of water and concomitant production of $\mathrm{H}^{+}$and $\mathrm{OH}$ ions.

Figure 2 shows that the cumulative permeation amount of angiotensin II and its antagonists with and without facilitated by an external electrical field. For angiotensin II and its antagonists, undetectable amounts of drug are transported across excised skin during passive diffusion (without facilitated by an external electrical field). In our early study, the smaller peptide, TRH (MW.=362), also didn't show any detectable amounts of drug permeated through excised skin during passive diffusion [2]. While during iontophoresis, under the monophase periodically pulsed current with the frequency of current: $1000 \mathrm{~Hz}$, duty cycle $50 \%$, offset $1 \mathrm{~mA}$, and the mean current $1 \mathrm{~mA}$, the permeation amount of angiotensin II and its antagonists increased with respect to the applied current. The cumulative amount of [Sar, Ala] angiotensin II was linearly increased as duration of iontophoresis increased. According to linear regression, the correlation coefficient is $R^{2}=0.968$.

The flux of angiotensin II and its antagonists, $J_{i}$, is attributed to three mechanism of transport--passive diffusion, electrically induced motion of ions, and electroosmotic convection, represented in Equation 1.

$$
\begin{aligned}
& J_{i}=J_{i p}+J_{i e}+J_{i v} \\
& J_{i}=-D \nabla C_{i}-\frac{D z_{i} F C_{i}}{R T} \nabla \phi+J_{i v}
\end{aligned}
$$

As experimental results show that $J_{i p}$ approaches zero and according to Pikal's model, $J_{i v}=L_{v e} \nabla \phi$, the flux is proportional to only the applied electrical field, $\nabla \phi$.

$$
J_{i}=-\frac{D z_{i} F C_{i}}{R T} \nabla \phi-L_{v e} \nabla \phi
$$

Experimental results showed that the resistance of the skin barrier soon approaches a steady value. As a result, the flux of angiotensin II and its antagonists is directly proportional to the total applied current density. The permeation flux of angiotensin II and [Sar,Ala] angiotnsin II were 3 and $12 \mu \mathrm{M} / \mathrm{cm}^{2} \mathrm{hr}$ respectively.

From Figure 2, we also found that after the current shut down, the passive permeation of angiotensin II and [Sar,Ala] angiotnsin Il were slightly increased compared to that of before iontophoresis, the flux from almost zero (undetectable) to $0.3 \mu \mathrm{M} / \mathrm{cm}^{2} \mathrm{hr}$. That meant that the skin structure was slightly changed possibly

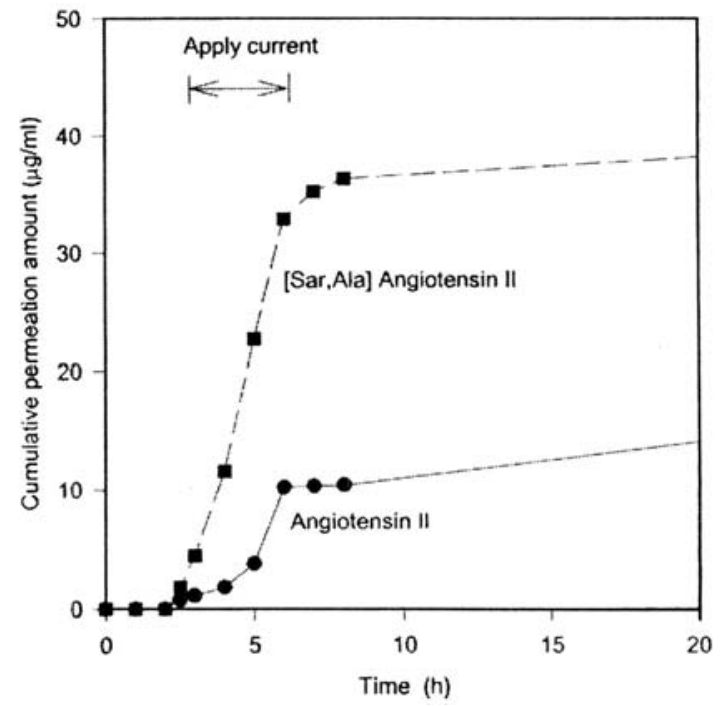

Fig. 2 Cumulative permeation amount of angiotensin II and its antagonists during monophased periodically pulse iontophoresis. $1 \mathrm{~mA}$, for 3 hours. 


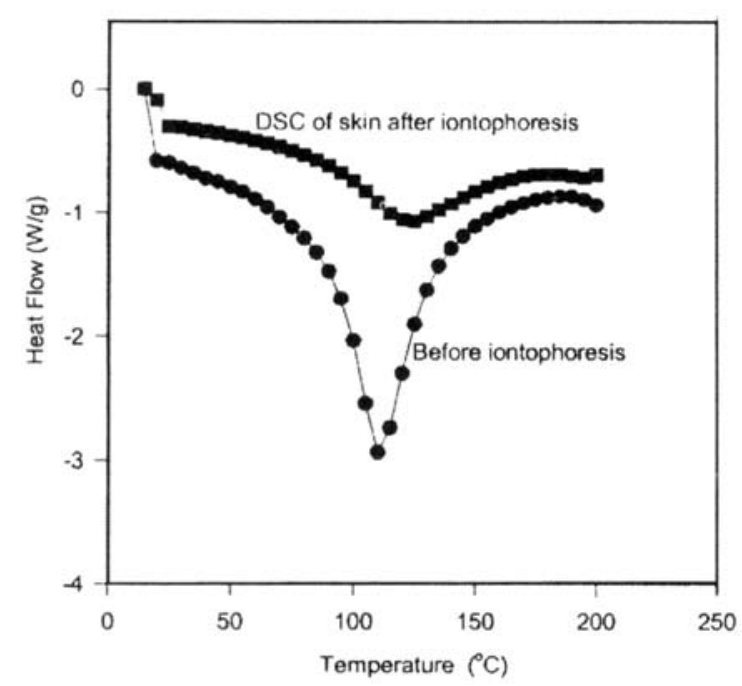

Fig. 3 Skin DSC.

due to the effect of iontophoresis or overhydrationed. From the DSC diagram of skin before and after iontophoresis (Figure 3), it confirmed that skin structure was slightly changed because the endothermal peak flattened. The structure of skin was loosely organized after iontophoresis as shown by low heat flow compared to the original one before iontophoresis. Overhydration of the skin during iontophoresis may be the major reasons.

Clemessy et al., [6] found that electroosmotic flow was more important in contribution to the iontophoretic transdermal delivery of peptides. Most of the current during iontophoresis was carried by buffer ions or electroosmotic flow, not due to the drug charge itself. Green [4] also considered the electroosmotic flow was more important. But if the convection term were the only factor dominating the transdermal permeation flux during iontophoresis, the permeation flux of angiotensin and its antagonists would be much the same in our experiments due to the same permeation condition. But actually, there have significant difference in the iontophoretic flux at the same permeation condition. At the current density of $0.28 \mathrm{~mA} / \mathrm{cm}^{2}$, the $\mathrm{H}_{2} \mathrm{O}$ flux gains 4-fold increase during iontophoresis, while for angiotensin II, 20-fold increase. From the correlation between angiotensin II flux versus $\mathrm{H}_{2} \mathrm{O}$ flux, Clemessy et al., [6] thought that iontohydrokinesis could be responsible for a significative part of the transport of angiotensin.

From the experimental results, Hatanaka et al., [12] suggested that the convective flow markedly contributed to the total skin permeability of a hydrophilic drug. In the visualization of iontophoretic pathways, Turner and Guy [5] found the larger molecules would accumulate within the pore section of hairfollics.

Therefore, for iontophoretic transdermal delivery of hydrophilic drug, such as peptides, the major path-

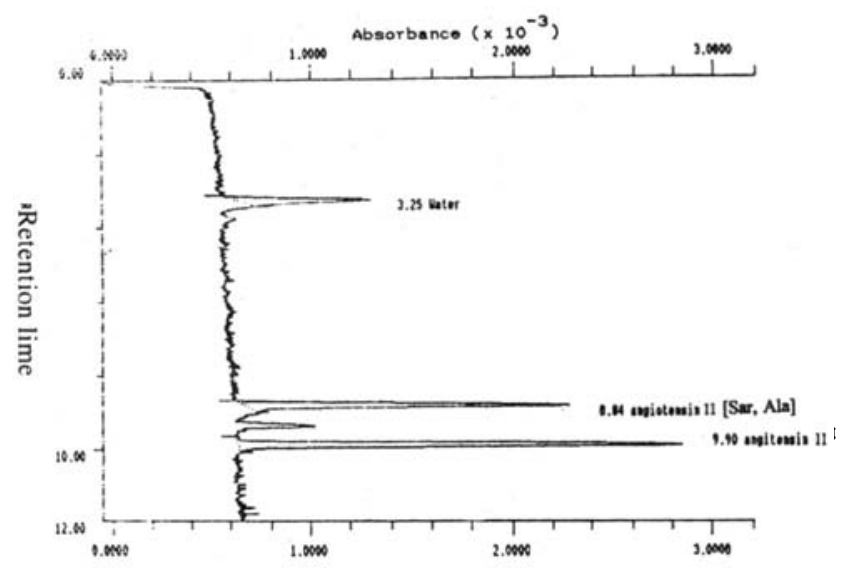

Fig. $4 \mathrm{CE}$ resisting time of angiotensin II and its antagonists in phosphate buffer under $15 \mathrm{kV}$ electrophoresis.

ways would be the pore channels within the skin. Considering these pore channels being composed of many of capillaries, the skin permeability can be related to the electrophoretic mobility of each capillary channel.

$$
\mu_{e p}=\frac{\nu_{e p}}{E}=\frac{L_{d} / t_{m}}{V / L_{t}}
$$

If the electroosmostic flow is the most important factor governing the iontophotetic delivery, the electroosmostic flow capability can be expressed by the following equation

$$
v_{e o}=\frac{\Xi \zeta}{4 \pi \eta} E
$$

The electrophoretic mobility of angiotensin II and its derivatives can be simulated by the capillary electrophoresis of these compounds. Figure 4 show the retention time of different derivatives of angiotensin 2 and itself. Under the condition $\mathrm{pH} 2,25 \mathrm{mM}$ phosphate buffer and $200 \mathrm{mM}$ Tween 20 . The electrophoretic mobility sequence of angiotensin II and its derivatives are

[Sar, Ala] angiotensin II > [Sar, Ile] angiotensin II > angiotensin II.

The retention time of [Sar, Ala] angiotensin II, [Sar, Ile] angiotensin II, and angiotensin II are 20.3, 22.9 and $29.6 \mathrm{~min}$ respectively [13]. Because in thecapillary electrophoresis, the major factors affecting the iontophoretic mobility are the molecular size and charges and in the phosphate buffer under $15 \mathrm{kV}$ electric field, the mobility of angiotensin II was slower than its antagonists, [Sar, Ala] angiotensin II and [Sar,Ile] angiotensin II (Figure4). The main reason may due to the different degree of dissociation of angiotensin II and its antagonists. From Table 1, we can see the charge of [Sar, Ala] angiotensin II and [Sar, Ile] angiotensin II are great than angiotensin II. At $\mathrm{pH} 7.4$, 
Table 1. Physical properties of angiotensin II and its antagonists.

\begin{tabular}{|c|c|c|c|c|c|c|}
\hline & & \multirow{2}{*}{ Drug } & Structure & \multirow{2}{*}{ M.W $^{*}$} & P $_{\text {I value }}$ & \multicolumn{4}{|c|}{ Charge } \\
\hline Angiotensin II & & 1046.2 & 7.7 & $1.8-4.5$ & $4.5-6.7$ & $6.7-10$ \\
\hline [Sar, Ala]AT2 $^{*}$ & & 926.1 & 9.9 & $2.3-6.7$ & $6.7-9.8$ & $9.8-10$ \\
\hline [Sar,Ile]AT2 $^{\circ}$ & & 968.2 & 9.9 & $2.4-6.7$ & $6.7-9.8$ & $9.8-10$ \\
\hline
\end{tabular}

AT2: Angiotensin II ; M.W.:Molecular weight.

Table 2 Partition coefficients of angiotensin II and its antagonists.

\begin{tabular}{|c|c|c|}
\hline Drug & \multicolumn{1}{|c|}{ Structure } & $\begin{array}{l}\text { Partition coeff. } \\
\text { Log } P_{\text {octano/water }}\end{array}$ \\
\hline Angiotensin II & Asp-Arg-Val-Tyr-Ile-His-Pro-Phe & -1.86 \\
\hline [Sar, Ala]AT2 $^{*}$ & Sar-Arg-Val-Tyr-Ile-His-Pro-Ala & -2.82 \\
\hline [Sar,Ile]AT2 $^{*}$ & Sar-Arg-Val-Tyr-Ile-His-Pro-Ile & -1.03 \\
\hline
\end{tabular}

the dissociation of angiotensin II was quite low. Most of the angiotensin II were in the neutral state. While the [Sar, Ala] angiotensin II and [Sar,Ile] angiotensin II are almost with same degree of dissociation. But the molecular size of [Sar, Ala] angiotensin II was a slight smaller than that of [Sar,Ile] angiotensin II, the iontophoretic mobility of [Sar, Ala] angiotensin Il is slightly higher than that of [Sar,Ile] angiotensin II.

Except the charge and size effects of peptide molecules, the hydrophobicity of peptide molecules also play a key factor affecting the iontophoretic transdermal permeation rate of peptides. Green et al., (1992, J. Control. Rel. 21:187-190, 1992) showed that the permeability of anionic Asp of the model peptide $\mathrm{CH}_{3}$-CO-Ala-X-Ala-NH-C( $\left.\mathrm{CH}_{3}\right)_{3}$ was highly lower than that of neutral amino acid residual. So the the iontophoretic permeation of angiotensin II ([Asp, ...,Phe]) was lower than that of [Sar, Ala] angiotensin II and [Sar,Ile] angiotensin II. The hydrophobicity of angiotensin II and its antagonists can be represented by the partition coefficient of peptides in octanol/water. The partition coefficient of [Sar, Ala] angiotensin II, [Sar, Ile] angiotensin II and angiotensin II were calculated from Abraham and Leo [14] and tabled in Table 2 . The hydrophobicity of angiotensin II and its antagonists are as follow.

[Sar, Ala] angiotensin II $>[\mathrm{Sar}, \mathrm{Ile}]$ angiotensin II $>$ angiotensin II.

Amino acid of sarcosine [Sar] in the angiotensin II antagonists is more hydrophobic than the amino acid of aspartic acid [Asp] in the angiotensin II. Including the charge and size effects, the angiotensin II moved most slowly, i.e. lowest electrophoretic mobility. So the lowest skin permeability.

\section{CONCLUSIONS}

Iontophoresis is a promising method to enhance permeation of peptides through skin. Transport of a model peptide drugs (angiotensin II and its antagonists) through excised rabbit pinna skin was enhanced with iontophoresis. The resulting flux enhanced by iontophoresis in the steady state was proportional to the applied current density and pulse duration. The delivery rate was proportional both to the current intensity and pulse duration of the stimulation. For the same current density, results showed that the permeation rate of [Sar, Ile] Angiotensin II > [Sar, Ala] Angiotensin II > Angiotensin II. Iontophoretic mobility and hydrophobicity were the key factors dominating the transdermal iontophoretic delivery rate of angiotensin II and its antagonists. Iontophoretic mobility can be simulated by the species mobility in capillary electrophoresis. And hydrophobic peptides permeated more quickly as compared with the hydrophilic peptides with similar primary structure and charge.

\section{ACKNOWLEDGMENT}

The authors wish to acknowledge the financial support of National Science Council of the Republic of China, Taiwan, NSC86-2213-E-002-022. 


\section{REFERENCES}

1. Banga $\mathrm{AK}$ and Chien $\mathrm{YW}$ : Iontophoretic Delivery of Drugs: Fundamentals, Developmentsand Biomedical Applications. J. Controlled Release 1988,7:1-24.

2. Huang YY and Wu SM : Transdermal iontophoretic delivery of thyrotropin releasing hormone across excised rabbit pinna skin. Drug Develop. Ind. Pharm., 1996; 21:1075-1081.

3. Stephen RL, Petelenz TJ and Jacobsen SC : Potential novel methods for insulin administration: iontophoresis. Biomed. Biochim. Acta.,1984, 43:553558.

4. Green PG, Hinz RS, Kim A, Cullander C, Yamane G, Szoka FC and Guy RH: Transdermal iontophoresis of amino acids and peptides in vitro, J. Control. Release, 1992, 21:187-190.

5. Turner NG, Ferry L, Price M, Cullander C and Guy RH : Iontophoresis of poly-L-lysines: The role of molecular weight? Pharm. Res.,1997, 14:13221331.

6. Clemessy M, Couarraze G, Bevan B and Puissieux F: Mechanisms involved in iontophoretic transport of angiotensin, Pharm. Res.,1995,12: 998-1002.

7. Bumette RR and Marrero D: Comparison between the iontophoretic and passive transport of thyrotropin releasing hormone across excised nude mouse skin. J. Pharm. Sci.,1986, 75: 738-743.
8. Li SK, Ghanem A, Peck KD and Higuchi W: Characterization of the transport pathways induced during low to moderate voltage iontophoresis in human epidermal membrane, J. Pharm. Sci.,1998, 18: 40-48.

9. Cullander C, Rao G and Guy RH: Why silver/silver chloride? Criteria for iontophoresis electrode, in Brain, K. R., James, V. J. and Walter, K. A.,(Eds), Prediction of Percutaneous Penetration Vol 3b, STS Publishing, Cardiff, UK, 1993, pp.381-390.

10. Lelawongs P, Liu JC, Siddiqui $O$ and Chien YW: Transdermal iontophoretic delivery of argininevasopressin I. Physico-chemical consideration, Int. J. Pharm., 1989, 56:13-22.

11. Linblad LE and Ekenvall L: Electrode material in iontophoresis. Pharm. Res., 1987,4: 438.

12. Hatanaka T. Manabe E. Sugibayashi K. and Morimoto $\mathrm{Y}$ : An application of the hydrodynamic pore theory to percutaneous absorption of drugs. Pharm. Res. 1994, 11:654-8.

13. Matsubara N, Koezuka K, and Terabe S. : Separation of eleven angiotensin II analogs by capillary electrophoresis with a nonionic surfactant in acidic medium. Electrophoresis, 1995, 16:580-583.

14. Abraham DJ and Leo AJ :Extension of the fragment method to calculate amino acid zwitterion and side chain partition coefficients. Proteins Struct. Func. Gen., 1987, 2:130-152. 